\title{
Are published characteristics of the ambulatory blood pressure generalizable to rural Chinese? The JingNing population study
}

\author{
Yan Li, ${ }^{a, b}$, Ji-Guang Wang ${ }^{a, b}$, Pingjin Gao ${ }^{a}$, Huifeng Guo ${ }^{a}$, Tim Nawrot ${ }^{b}$, \\ Guliang Wang ${ }^{\mathrm{a}}$, Yuesheng Qian ${ }^{\mathrm{a}}$, Jan A Staessen ${ }^{\mathrm{b}}$ and Dingliang $\mathrm{Zhu}^{\mathrm{a}}$
}

Objective We investigated the ambulatory blood pressure (BP) in rural Chinese and compared its characteristics with those reported in other population-based studies.

Methods We enrolled inhabitants from six villages of the JingNing County, China. We recorded the ambulatory BP using 90207 SpaceLabs monitors. Trained physicians measured the conventional BP at the participants' homes. Hypertension was defined as a conventional BP of $\geq 140 / \geq 90 \mathrm{mmHg}$ or a condition requiring the intake of antihypertensive drugs. Using MEDLINE, we searched for population-based studies on ambulatory BP monitoring.

Results The 356 participants (12-86 years) included 192 (53.9\%) women and 117 (32.9\%) hypertensive patients. In all participants, systolic/diastolic BP averaged 129/80 $\mathrm{mmHg}$ at home. The ambulatory BP means were 121/77 $\mathrm{mmHg}$ over $24 \mathrm{~h}, 126 / 81 \mathrm{mmHg}$ during daytime (0800 to $1800 \mathrm{~h}$ ) and $112 / 70 \mathrm{mmHg}$ during night-time (2200 to $0400 \mathrm{~h}$ ). The awake and asleep BPs averaged 126/82 and $112 / 70 \mathrm{mmHg}$, respectively. Using previously published definitions of daytime $(1000$ to $2000 \mathrm{~h})$ and night-time (midnight to $0600 \mathrm{~h}$ ) instead of those given above, inflated the BP differences with the awake and asleep BPs from $0.4 / 0.2$ to $1.2 / 1.0 \mathrm{mmHg}$ and from $0.3 / 0$ to $1.4 / 1.6 \mathrm{mmHg}$, respectively. Compared with daytime values, conventional $B P$ was $2.7 / 3.1 \mathrm{mmHg}$ lower in normotensive individuals, but $14.9 / 1.3 \mathrm{mmHg}$ higher in hypertensive patients. In our normotensive individuals, the whole-day and night-time diastolic BPs were from 1 to $4 \mathrm{mmHg}$ and from 3 to $7 \mathrm{mmHg}$ higher than in five other population studies in Caucasians or Japanese, whereas night-time BP in our

\section{Introduction}

Ambulatory blood pressure monitoring is increasingly used in clinical practice [1,2]. Current guidelines and consensus documents propose various operational thresholds for the clinical use of ambulatory blood pressure monitoring $[3,4]$. Initially, these thresholds were based on large-scale epidemiological studies in well-defined professional groups [5,6], in normotensive [7] and hypertensive individuals [8,9] and in the population at large [10-17]. Subsequently, they have been validated in prospective outcome studies in hypertensive patients [18-24] and in the longitudinal Ohasama study in Japan [25]. participants was $9 / 5 \mathrm{mmHg}$ lower than in Chinese living in Taiwan.

Conclusions We demonstrated significant differences in the characteristics of the ambulatory blood pressure across Asian and Caucasian populations. To what extent different activity patterns and genetic and environmental factors explain this context-dependency remains to be clarified. Blood Press Monit 10:125-134 (c) 2005 Lippincott Williams \& Wilkins.

Blood Pressure Monitoring 2005, 10:125-134

Keywords: ambulatory blood pressure, conventional blood pressure, population

${ }^{a}$ Centre for Epidemiological Studies and Clinical Trials, Ruijin Hospital, Shanghai Institute of Hypertension, Shanghai Second Medical University, Shanghai, China and ' Studiecoördinatiecentrum, Hypertensie en Cardiovasculaire Revalidatie Eenheid, Departement Moleculair en Cardiovasculair Onderzoek, Katholieke Universiteit Leuven, Leuven, Belgium.

Sponsorship: This investigation was funded by the Bilateral Scientific and Technical Cooperation between China and Flanders (BIL02/10, 2003-2005) and by the Chinese Ministry of Science and Technology, Beijing, China (2002BA711A05, 2001AA227061 and G2000056904).

Correspondence to Dingliang Zhu, Ruijin Hospital, Shanghai Institute of Hypertension, Ruijin 2nd Road 197, 200025 Shanghai, China. Tel: + 862164370045 ext 610901; fax: + 86215465 4498; e-mail: f97075@guomai.sh.cn

Requests for reprints to Jan A Staessen, MD, PhD, Studiecoördinatiecentrum, Laboratorium Hypertensie, Campus Gasthuisberg, Herestraat 49, B-3000 Leuven, Belgium. Tel: +32 1634 7104; fax: +32 1634 7106; e-mail: jan.staessen@med.kuleuven.ac.be

Received 3 August 2004 Revised 8 December 2004 Accepted 20 December 2004

Until now, most published studies on operational thresholds for ambulatory blood pressure monitoring involved individuals recruited in industrialized countries $[10,12,15,17]$ or from urban environments [6,11]. To the best of our knowledge, few studies have been performed in remotely living rural Chinese [14]. We therefore investigated in a random population sample to what extent previously published characteristics of the ambulatory blood pressure can be extrapolated to a rural population living in a remote rural mountainous area approximately $500 \mathrm{~km}$ south of Shanghai. 


\section{Methods Study population}

In the framework of an ongoing Chinese study on genes involved in hypertension, we visited all homes in six villages randomly selected from the JingNing County, in which approximately $90 \%$ of the inhabitants are She Chinese, and the remainder belong to the Han ethnicity. The literacy rate among adults is $65.5 \%$ and life expectancy at birth is 74.7 years. We invited family members to take part in our study, if at least two offspring with a minimum age of 12 years and one parent were available for examination. Of 839 eligible individuals, 509 (61.7\%) participated. At the time of writing of this report, 366 individuals had their ambulatory blood pressure measured. The Ethics Committees of Ruijin Hospital and the Shanghai Second Medical University approved the study protocol. All participants gave informed written consent.

We excluded four individuals from analysis because their conventional blood pressure measured at home was unavailable and six individuals because their ambulatory recordings did not meet our pre-specified quality criteria $[8,12,16]$, namely more than $20 \mathrm{~h}$ of recording and more than 10 and five readings for the computation of the daytime and night-time means, respectively. Thus, the number of participants included in the present analysis was 356.

\section{Ambulatory blood pressure measurement}

At the first contact with each participant, the observers ascertained that there was no clinically significant difference in the blood pressure readings obtained at the left and right arm. After a $5 \mathrm{~min}$ rest in the sitting position, the blood pressure was measured on both arms, always starting with the non-dominant arm. The interval between these two readings had to be less than $1 \mathrm{~min}$. If systolic and diastolic blood pressure were within $10 \mathrm{mmHg}$ at either side, all blood pressure readings were obtained using the non-dominant arm. In the other individuals, the arm giving the highest blood pressure readings was chosen for all blood pressure measurements.

We programmed oscillometric SpaceLabs 90207 monitors (SpaceLabs Inc., Redmond, Washington, USA) [26] to obtain blood pressure measurements with an interval of $20 \mathrm{~min}$ from 0800 until $2200 \mathrm{~h}$ and every $45 \mathrm{~min}$ from 2200 to $0800 \mathrm{~h}$. The calibration of these devices was checked monthly against a mercury column.

If the ambulatory recordings were longer than $24 \mathrm{~h}$, only the first $24 \mathrm{~h}$ were used for analysis. Intra-individual means of the ambulatory measurements were weighted by the time interval between successive readings [27]. Considering the pattern of daily activities of the study participants (90\% farmers), we defined daytime and night-time as the intervals ranging from 0800 to $1800 \mathrm{~h}$ and from 2200 to $0400 \mathrm{~h}$, respectively. These fixed clocktime intervals [12,27] eliminate the transition periods in the morning and evening during which the blood pressure rapidly changes in most individuals. On monitoring days, the participants kept a diary, in which they noted the time of going to bed in the evening and getting up in the morning and from which we determined the awake and asleep periods of the day.

\section{Auscultatory blood pressure readings}

Five physicians repeatedly visited the participants at their homes. By means of mercury sphygomanometer, they measured the participants' blood pressure five times consecutively on at least two occasions 3 to 4 weeks apart after the participants had rested for $5 \mathrm{~min}$ in the sitting position. Systolic and diastolic (phase V) pressures were determined to the nearest $2 \mathrm{mmHg}$ according to the recommendations of the European Society of Hypertension [3]. As the arm circumference of all participants was less than $32 \mathrm{~cm}$, we only used standard cuffs, which had an inflatable bladder with a length of $22 \mathrm{~cm}$ and a width of $12 \mathrm{~cm}$. For analysis, we averaged the five readings of the first home visit, because in most epidemiological studies blood pressure is only measured at one occasion. During the home visits, the physicians administered a standardized questionnaire to inquire into each participant's smoking habits, alcohol consumption and intake of medications.

In agreement with current guidelines [3], hypertension and normotension were defined on the basis of conventional sphygmomanometry. Hypertension was present, if the conventional blood pressure was equal to or exceeded $140 \mathrm{mmHg}$ systolic or $90 \mathrm{mmHg}$ diastolic, or if the individuals were on antihypertensive medication irrespective of their blood pressure.

The physicians involved in blood pressure measurement received special training. They only qualified as observer, if all their blood pressure readings $(n=20)$ from a video film featuring a falling mercury column with Korotkoff sounds (Blood Pressure Measurement, British Medical Journal, BMA House, London, UK) were within $5 \mathrm{mmHg}$ of the reference standard.

\section{Comparison with other epidemiological studies}

To compare our present finding with other large-scale epidemiological studies, we performed an electronic search of the literature using MEDLINE and the key words 'ambulatory blood pressure monitoring' and 'population'. We did not restrict our search by language. We considered studies for inclusion in our comparative analyses, if they had an overall sample size of at least 300 , and if they included separate statistics for normotensive participants. 


\section{Statistical methods}

Database management and statistical analyses were performed with SAS software, version 8.1. (The SAS Institute Inc., Cary, North Carolina, USA). Departure from normality was evaluated by Shapiro-Wilk's statistic [28] and skewness by the computation of the coefficient of skewness, namely the third moment about the mean divided by the cube of the standard deviation [29]. The normal distribution was used to determine the significance of the coefficient of skewness [29].

Our statistical methods included Student's $t$-test, the standard normal z-test for the comparison of large samples, the chi-squared statistic, and simple and multiple linear regression [30]. We performed multivariate analysis of variance to test the null hypothesis of no differences between the parameters of regression equations [30]. Between-group comparisons of correlation coefficients were done by means of Fisher's z-transformation [31].

\section{Results}

\section{Characteristics of the participants}

Men $(n=164)$ and women $(n=192)$ had similar age (mean \pm SD, $46 \pm 16$ years; range, 12-86). In men, mean values for the anthropometric measurements were $57.2 \pm$ $10.0 \mathrm{~kg}$ for body weight, $22.0 \pm 3.0 \mathrm{~kg} / \mathrm{m}^{2}$ for body-mass index, and $24.3 \pm 2.3 \mathrm{~cm}$ for upper arm circumference; in women, these averages were $53.0 \pm 8.8 \mathrm{~kg}, 23.1 \pm 3.1$ $\mathrm{kg} / \mathrm{m}^{2}$, and $23.9 \pm 2.5 \mathrm{~cm}$, respectively.

Of the 356 participants, 96 (27.0\%; all men) were smokers and 163 (45.8\%; 120 men and 43 women) reported regular alcohol intake. Among smokers, median tobacco use was 19 cigarettes per day (range, 2-40). Among drinkers, median alcohol consumption was $46 \mathrm{~g} /$ day (range, 3-200). Of the study participants, 268 $(75 \%)$ individuals consumed tea on a daily basis, but nobody reported drinking coffee. Three $(0.8 \%)$ participants had diabetes mellitus, because their fasting glucose exceeded $7 \mathrm{mmol} / \mathrm{l}$. No participants were on antidiabetic drug treatment. Only one woman reported taking the contraceptive pill.

\section{Ambulatory blood pressure measurement}

The days on which the ambulatory blood pressure recordings took place were similarly distributed among men and women (18.8\% of the recordings were performed on Mondays, $18.8 \%$ on Tuesdays, $11.5 \%$ on Wednesdays, $14.0 \%$ on Thursdays, $9.9 \%$ on Fridays, 9.8\% on Saturdays and $17.4 \%$ on Sundays).

In all 356 participants, the distributions of the 24-h systolic and diastolic blood pressure departed from normality $(P<0.001$; Fig. 1$)$ and were positively skewed $(P<0.001)$; the coefficients of skewness were 1.03 and
0.66 , respectively. The 24-h ambulatory blood pressure averaged $121.0 \mathrm{mmHg}$ [95\% confidence interval $(95 \%$ CI), 119.3-122.6] systolic and $77.0 \mathrm{mmHg}$ (95\% CI, 76.0-78.1) diastolic. The daytime blood pressure averaged $125.8 \mathrm{mmHg}$ (95\% CI, 124.2-127.4) systolic and $81.4 \mathrm{mmHg}$ (95\% CI, 80.4-82.4) diastolic. The nighttime averages were $112.3 \mathrm{mmHg}$ (95\% CI, 110.4-114.1) and $70.0 \mathrm{mmHg}$ (95\% CI, 68.8-71.2), respectively. Additional statistics for the ambulatory blood pressure are presented by gender and age $(\leq 39,40-59$, and $\geq 60$ years) in Table 1 . The average blood pressure values and corresponding 95\% CI for any hour during the day are shown in Figure 2 for men and Figure 3 for women. Mean values in beats per min for the 24-h, daytime and nighttime pulse rate were 72.4 (95\% CI, 54.8-88.9), 79.3 (95\% CI, 58.9-99.7) and 62.1 (95\% CI, 45.6-78.6), respectively.

As shown in Table 2, among the 343 participants, who had completed a diary, the awake blood pressure averaged $126.1 \mathrm{mmHg}$ (95\% CI, 124.4-127.7) systolic and 81.5 $\mathrm{mmHg}$ (95\% CI, 80.5-82.6) diastolic, while the averages during sleep were $112.3 \mathrm{mmHg}$ (95\% CI, 110.5-114.1) and $69.6 \mathrm{mmHg}$ (95\% CI, 68.5-70.8), respectively. Irrespective of hypertension status, the means determined according to the diary method were within $0.5 \mathrm{mmHg}$ of those computed from fixed clock-time intervals. In exploratory analyses, we also defined daytime and night-time as in our previous publications $[12,32,33]$

Fig. 1

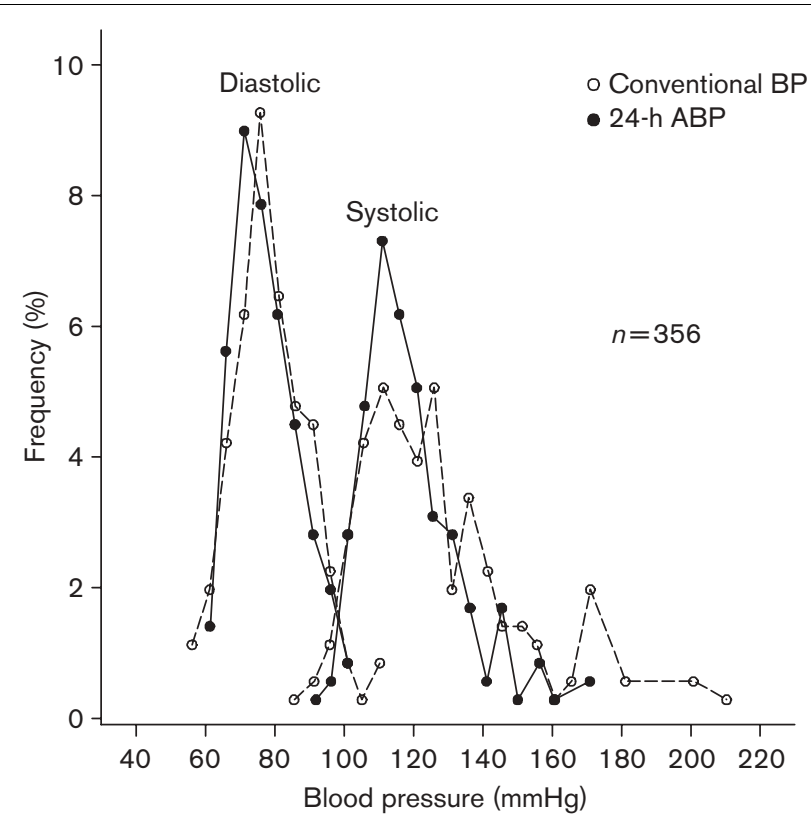

The distribution of the systolic (right) and diastolic (left) blood pressures in 356 individuals drawn at random from a rural Chinese population. Dots denote the 24-h ambulatory blood pressure (24-h ABP) and circles the conventional blood pressure measured at home (Conventional BP). 
Table 1 Systolic/diastolic pressures in $\mathbf{3 5 6}$ participants randomly selected from the JingNing population

\begin{tabular}{|c|c|c|c|c|c|c|c|c|c|}
\hline & \multicolumn{4}{|c|}{ Men } & \multicolumn{4}{|c|}{ Women } & \multirow[t]{2}{*}{ Both sexes } \\
\hline & $\leq 39$ years & $40-59$ years & $\geq 60$ years & All men & $\leq 39$ years & $40-59$ years & $\geq 60$ years & All women & \\
\hline Number & 74 & 50 & 40 & 164 & 88 & 65 & 39 & 192 & 356 \\
\hline \multicolumn{10}{|l|}{ Conventional $^{\mathrm{a}}$} \\
\hline Mean & $121 / 78$ & $131 / 83$ & $141 / 80$ & $129 / 80$ & $115 / 76$ & $135 / 82$ & $151 / 83$ & $129 / 79$ & $129 / 80$ \\
\hline SD & $18 / 12$ & $20 / 11$ & $25 / 11$ & $22 / 11$ & $17 / 12$ & 24/12 & 27/12 & 26/13 & 24/12 \\
\hline $\mathrm{P}_{5}$ & $98 / 60$ & $105 / 65$ & $110 / 66$ & $102 / 64$ & $92 / 59$ & $102 / 60$ & $103 / 63$ & $96 / 60$ & $100 / 61$ \\
\hline$P_{50}$ & $118 / 77$ & $126 / 83$ & $136 / 78$ & $125 / 79$ & $112 / 75$ & $132 / 80$ & $145 / 83$ & $122 / 78$ & $124 / 78$ \\
\hline $\mathrm{P}_{90}$ & $138 / 95$ & $162 / 94$ & $173 / 95$ & $159 / 95$ & $138 / 92$ & $171 / 96$ & $189 / 98$ & $170 / 95$ & $165 / 95$ \\
\hline$P_{95}$ & $151 / 102$ & $171 / 105$ & $191 / 99$ & $171 / 102$ & $153 / 95$ & $174 / 100$ & $199 / 105$ & $178 / 100$ & $177 / 101$ \\
\hline \multicolumn{10}{|l|}{ Daytime } \\
\hline Mean & $123 / 80$ & $130 / 86$ & $131 / 82$ & $127 / 82$ & $117 / 78$ & $128 / 84$ & $138 / 83$ & $125 / 81$ & $126 / 81$ \\
\hline SD & $12 / 10$ & $14 / 8$ & $16 / 9$ & $14 / 10$ & $11 / 9$ & $15 / 9$ & $19 / 11$ & $17 / 10$ & $16 / 10$ \\
\hline $\mathrm{P}_{5}$ & $106 / 65$ & $109 / 73$ & $111 / 69$ & $109 / 68$ & $100 / 67$ & $108 / 68$ & $104 / 69$ & $104 / 68$ & $105 / 68$ \\
\hline$P_{50}$ & $121 / 78$ & $128 / 86$ & $125 / 82$ & $124 / 81$ & $115 / 75$ & $124 / 82$ & $135 / 81$ & $121 / 79$ & $122 / 80$ \\
\hline $\mathrm{P}_{90}$ & $137 / 91$ & $144 / 96$ & $152 / 95$ & $144 / 94$ & $133 / 89$ & $152 / 95$ & $162 / 100$ & $152 / 95$ & $147 / 95$ \\
\hline $\mathrm{P}_{95}$ & $144 / 98$ & $157 / 99$ & $159 / 97$ & $154 / 98$ & $138 / 97$ & $156 / 98$ & $167 / 104$ & $159 / 100$ & $157 / 99$ \\
\hline \multicolumn{10}{|l|}{ Night-time } \\
\hline Mean & $107 / 66$ & $114 / 74$ & $123 / 75$ & $113 / 71$ & $101 / 64$ & $114 / 73$ & $131 / 75$ & $112 / 69$ & $112 / 70$ \\
\hline SD & $12 / 11$ & $17 / 10$ & $16 / 10$ & $16 / 11$ & $11 / 9$ & $17 / 11$ & $22 / 13$ & $19 / 12$ & $18 / 11$ \\
\hline$P_{5}$ & $88 / 50$ & $94 / 61$ & $100 / 59$ & $94 / 56$ & $87 / 52$ & $95 / 58$ & $94 / 55$ & $89 / 55$ & $90 / 55$ \\
\hline$P_{50}$ & $106 / 65$ & $109 / 74$ & $120 / 76$ & $109 / 69$ & $98 / 62$ & $111 / 72$ & $130 / 73$ & $107 / 67$ & $109 / 68$ \\
\hline $\mathrm{P}_{90}$ & $118 / 79$ & $129 / 83$ & $148 / 89$ & $134 / 84$ & $115 / 75$ & $139 / 89$ & $153 / 91$ & $140 / 86$ & $138 / 85$ \\
\hline$P_{95}$ & $123 / 86$ & $136 / 94$ & $150 / 91$ & $147 / 90$ & $122 / 82$ & $144 / 91$ & $179 / 105$ & $150 / 90$ & $147 / 90$ \\
\hline \multicolumn{10}{|l|}{ Whole day } \\
\hline Mean & $117 / 75$ & $125 / 82$ & $127 / 79$ & $122 / 78$ & $111 / 72$ & $123 / 79$ & $135 / 80$ & $120 / 76$ & $121 / 77$ \\
\hline SD & $11 / 10$ & $15 / 8$ & $15 / 8$ & $14 / 9$ & $11 / 9$ & $15 / 9$ & $18 / 11$ & $17 / 10$ & $16 / 10$ \\
\hline$P_{5}$ & $102 / 63$ & $106 / 68$ & $107 / 67$ & $105 / 65$ & $97 / 62$ & $106 / 66$ & $106 / 64$ & $101 / 64$ & $102 / 64$ \\
\hline$P_{50}$ & $116 / 72$ & $121 / 81$ & $126 / 77$ & $119 / 77$ & $109 / 71$ & $118 / 78$ & $137 / 77$ & $115 / 75$ & $117 / 76$ \\
\hline $\mathrm{P}_{90}$ & $129 / 86$ & $139 / 91$ & $145 / 91$ & $137 / 90$ & $125 / 83$ & $146 / 93$ & $159 / 97$ & $146 / 92$ & $143 / 92$ \\
\hline $\mathrm{P}_{95}$ & $134 / 94$ & $145 / 93$ & $156 / 93$ & $145 / 93$ & $128 / 92$ & $150 / 95$ & $169 / 100$ & $154 / 96$ & $154 / 95$ \\
\hline
\end{tabular}

Daytime ranges from 0800 to $1800 \mathrm{~h}$ and night-time from 2200 to $0400 \mathrm{~h}$.

${ }^{a}$ Average of five consecutive readings obtained by conventional sphygmomanometry at participant's home.

as the intervals ranging from 10:00 to $20: 00 \mathrm{~h}$ and from midnight to 06:00 h, respectively. Applying these definitions, increased the differences between the awake and daytime blood pressures to $1.2 \mathrm{mmHg}$ (95\% CI, $0.8-1.5$; $P<0.001)$ systolic and $1.0 \mathrm{mmHg}(95 \%$ CI, $0.8-1.2$; $P<0.001)$ diastolic and those between the asleep and night-time blood pressures to $1.4 \mathrm{mmHg}$ (95\% CI, $0.9-1.8 ; P<0.001)$ and $1.6 \mathrm{mmHg}$ (95\% CI, $1.3-1.9$; $P<0.001)$, respectively.

A total of 117 (32.9\%) participants were hypertensive, because their conventional blood pressure measured in the absence of treatment reached diagnostic thresholds $(n=67 ; 57.3 \%)$ or because they were on treatment with antihypertensive drugs $(n=50 ; 42.7 \%)$. When only the 239 normotensive individuals were considered in the analysis, the 24-h blood pressure averaged $113.6 \mathrm{mmHg}$ (95\% CI, 112.4-114.7) systolic and $73.1 \mathrm{mmHg}(95 \%$ CI72.2-74.0) diastolic. The daytime blood pressure in the normotensive individuals was $118.6 \mathrm{mmHg} \quad(95 \%$ CI, 117.4-119.8) systolic and $77.6 \mathrm{mmHg}$ (95\% CI, 76.6-78.5) diastolic, whereas the blood pressures at night were $104.7 \mathrm{mmHg}$ (95\% CI, 103.3-106.1) and $65.5 \mathrm{mmHg}$ (95\% CI, 64.5-66.6), respectively. Additional statistics for the ambulatory blood pressure measurements in normotensive individuals are presented in Table 3.

\section{Conventional compared with daytime blood pressure}

We obtained 3560 blood pressure readings at the participants' homes (five per participant). In terms of digit preference, $16.2 \%$ of the readings ended in $0,20.3 \%$ in $2,19.7 \%$ in $4,21.1 \%$ in 6 and $22.7 \%$ in 8.

In the total study sample $(n=356)$, the conventional blood pressure averaged $128.9 \mathrm{mmHg}$ (95\% CI, 126.4131.4) systolic and $79.7 \mathrm{mmHg}$ (95\% CI, 78.5-81.0) diastolic (Table 1). In the 239 normotensive individuals (Table 3), the conventional blood pressure averaged $115.9 \mathrm{mmHg} \quad(95 \%$ CI, 114.5-117.4) systolic and $74.4 \mathrm{mmHg} \quad(95 \%$ CI, 73.4-75.5) diastolic. In 117 hypertensive patients, these values were $155.4 \mathrm{mmHg}$ (95\% CI, 151.7-159.1) and $90.5 \mathrm{mmHg}$ (95\% CI, 88.592.5), respectively. Differences between the conventional and daytime blood pressures according to the absence or presence of hypertension and treatment status are presented in Table 4. At home, the conventionally measured pulse rate averaged 72.2 beats per min $(95 \%$ CI, 54.6-89.8).

\section{Age as blood pressure determinant}

For the conventional as well as the 24-h ambulatory blood pressure, the relation with age was linear for systolic pressure and curvilinear for diastolic pressure. A 
Fig. 2

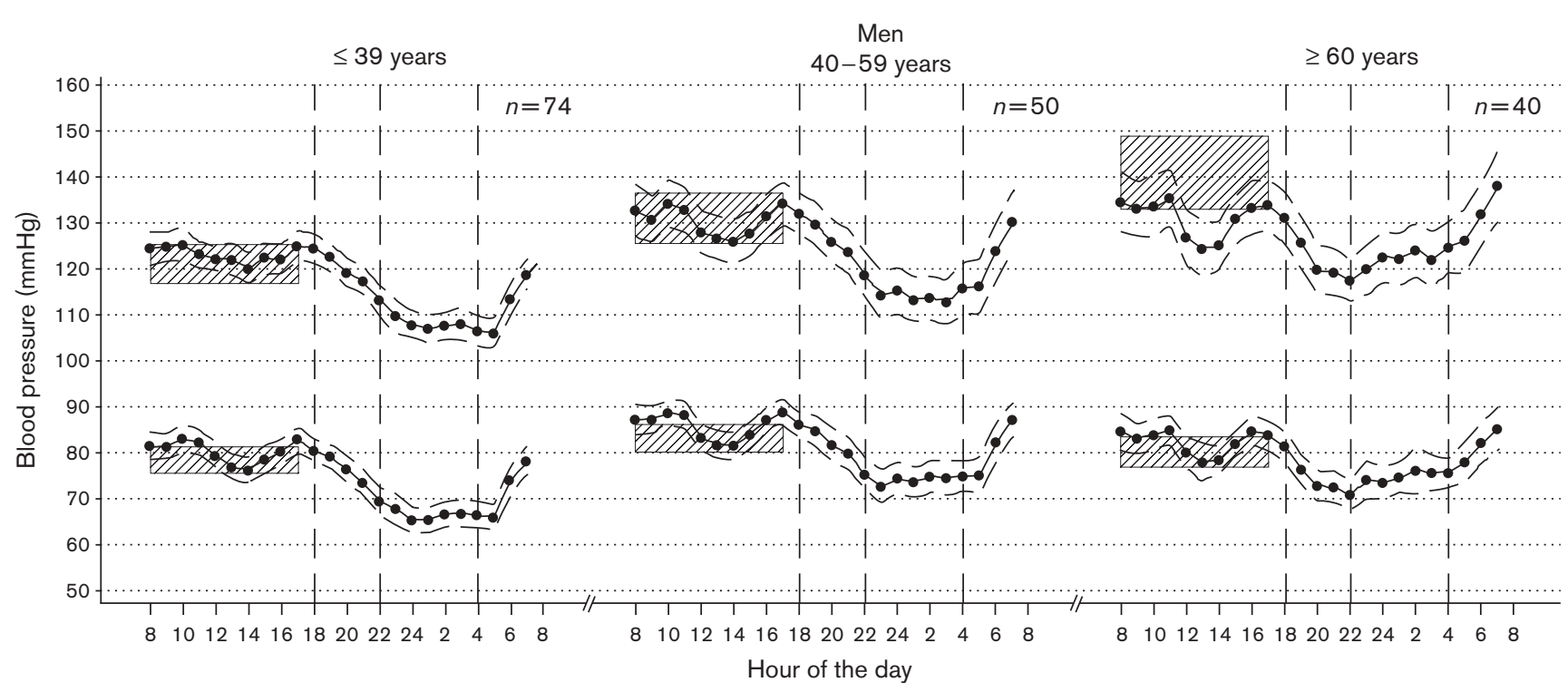

Ambulatory systolic and diastolic blood pressures in men of three age categories. The hourly means with $95 \%$ confidence interval are presented. The shaded bands indicate the $95 \%$ confidence interval for the conventional blood pressure measured at home (average of five readings in the sitting position).

Fig. 3

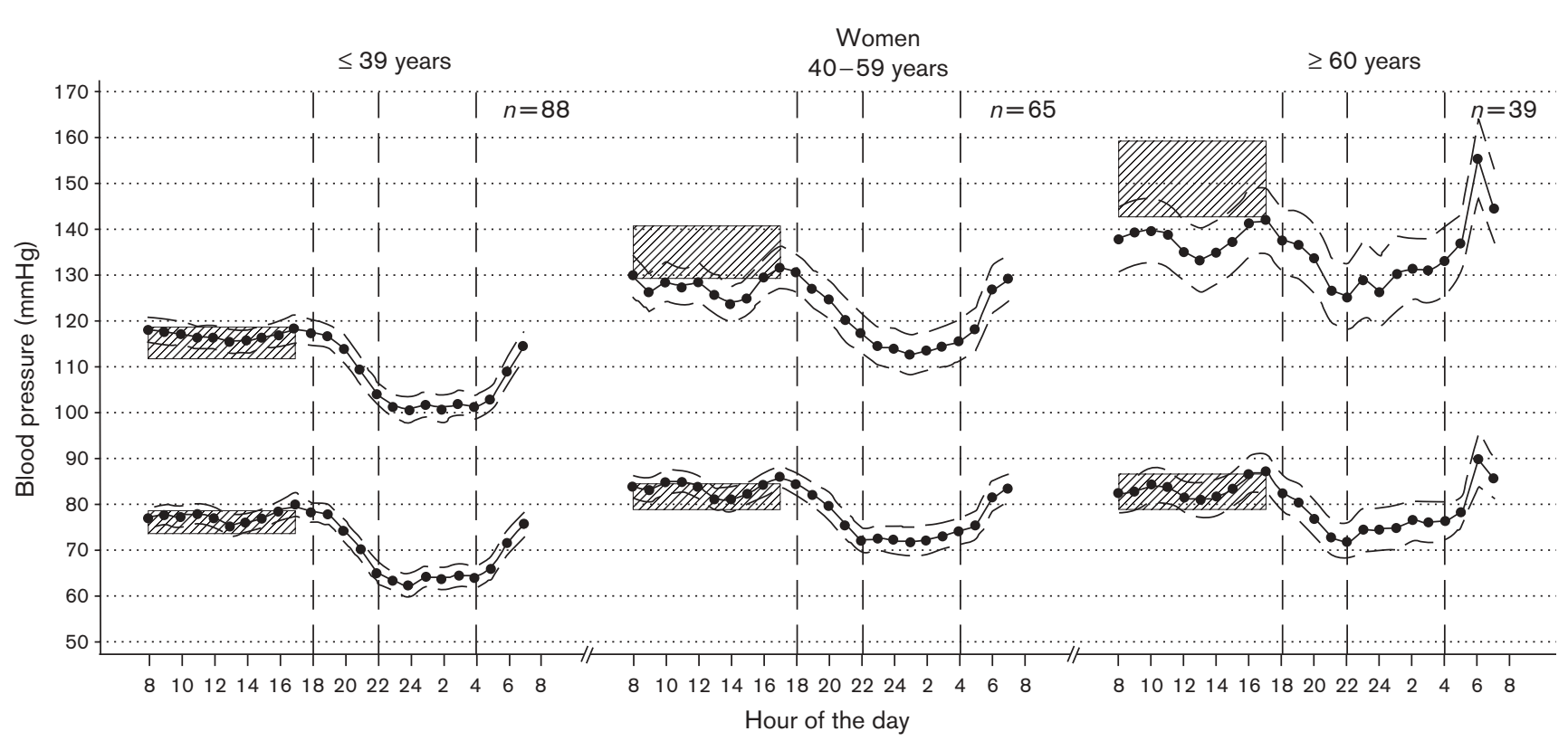

Ambulatory systolic and diastolic blood pressures in women in three age categories. For further details see Fig. 2.

regression model including both the linear and squared terms of age was therefore only required for diastolic blood pressure. Multivariate analyses to compare the parameters of the regression equations demonstrated that in men and in women alike the conventional systolic pressure increased steeper $(P<0.001)$ with age than the daytime systolic pressure, whereas for the diastolic pressure the relations with age were similar $(P>0.47)$ for the two types of measurement (Fig. 4). 
Table 2 Differences between ambulatory blood pressure means determined according to diary or fixed clock-time intervals

\begin{tabular}{|c|c|c|c|c|c|c|}
\hline \multirow[b]{2}{*}{ Wakefulness } & \multicolumn{3}{|c|}{ All participants with diary $(n=343)$} & \multicolumn{3}{|c|}{ Normotensive individualts with diary $(n=232)$} \\
\hline & Mean $\pm \mathrm{SD}(\mathrm{mmHg})$ & Difference $^{\mathrm{a}}(\mathrm{mmHg})$ & $P$ & Mean $\pm \mathrm{SD}(\mathrm{mmHg})$ & Difference $^{\mathrm{a}}(\mathrm{mmHg})$ & $P$ \\
\hline \multicolumn{7}{|l|}{ Awake } \\
\hline Systolic & $126.1 \pm 15.7$ & $0.36(0.11-0.61)$ & 0.004 & $118.9 \pm 9.4$ & $0.20(-0.07$ to 0.47$)$ & 0.14 \\
\hline Diastolic & $81.5 \pm 9.8$ & $0.17(-0.00$ to 0.34$)$ & 0.06 & $77.8 \pm 7.2$ & $0.18(-0.02$ to 0.37$)$ & 0.08 \\
\hline \multicolumn{7}{|l|}{ Asleep } \\
\hline Systolic & $112.3 \pm 16.9$ & $0.35(-0.01$ to 0.70$)$ & 0.05 & $105.1 \pm 10.1$ & $0.33(-0.05$ to 0.71$)$ & 0.09 \\
\hline Diastolic & $69.6 \pm 10.8$ & $-0.10(-0.37$ to 0.17$)$ & 0.47 & $65.5 \pm 8.0$ & $0.02(-0.29$ to 0.33$)$ & 0.91 \\
\hline
\end{tabular}

${ }^{a}$ Mean differences ( $95 \%$ confidence interval) were calculated by subtracting daytime ( 0800 to $1800 \mathrm{~h}$ ) from awake blood pressure and night-time (2200 to $0400 \mathrm{~h}$ ) from asleep blood pressure.

Fig. 4

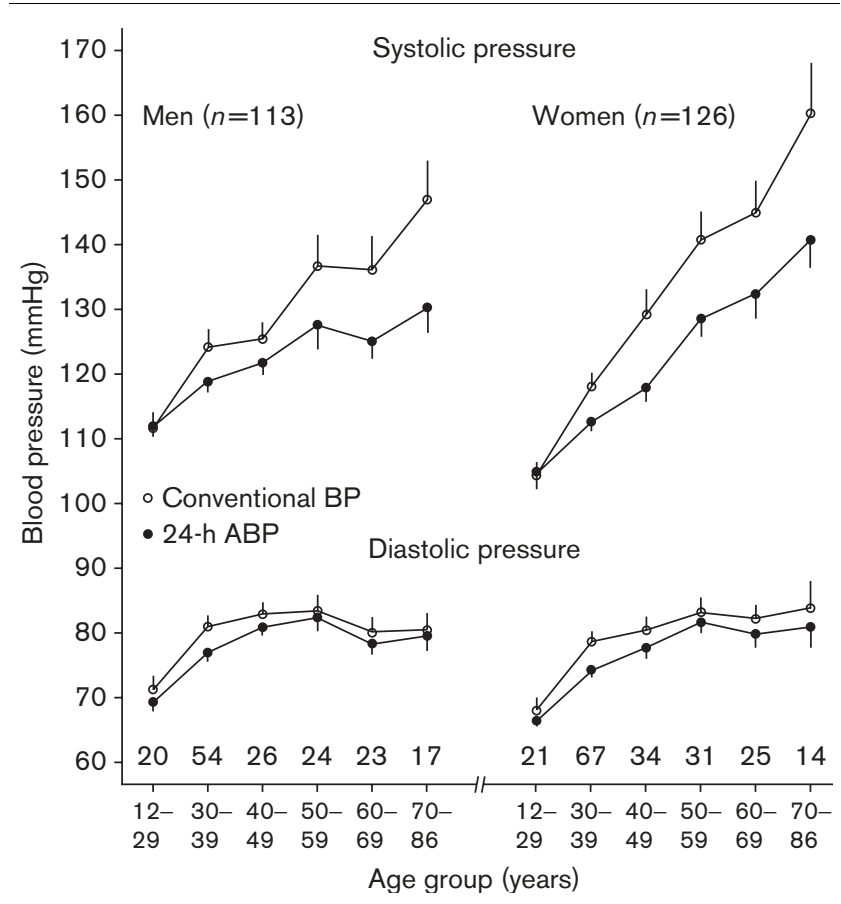

The conventionally measured blood pressure (average of five readings at home, open symbols) and the 24-h ambulatory blood pressure (closed symbols) by age in men and women. Values are means \pm SEM.

\section{Comparison with other population studies}

Our electronic search identified nine other large-scale epidemiological studies on ambulatory blood pressure monitoring [6,10-17]. The sample size of these studies ranged from 352 to 1855 . To compare our present data with those previously published, we excluded one British [15] and two Danish studies [13,17], because the reports did not include separate statistics for normotensive individuals. Among the six remaining studies [6,10-12, 14,16], The conventional blood pressure was measured either at an examination center $[6,10,14]$ or at the participants' homes $[11,12,16]$. Mean age ranged from 33 to 54 years.

Among normotensive individuals aged 20 years or more, the diastolic blood pressure as measured by ambulatory monitoring during night-time and the whole day was consistently higher among Chinese recruited in JingNing and Taiwan than in all other countries; the mean differences in night-time diastolic blood pressure ranged from 3 to $11 \mathrm{mmHg}$ (Table 5). Furthermore, the nighttime systolic blood pressure was 8 to $10 \mathrm{mmHg}$ higher in Chinese living in Taiwan than in all other populations, including our JingNing individuals. With regard to daytime and conventional blood pressures, no consistent pattern emerged in the between-population comparisons (Table 5).

\section{Discussion}

In the present study, we recorded the ambulatory blood pressure in Chinese randomly recruited from the population of a remote rural area. To investigate to what extent previously published characteristics of ambulatory blood pressure measurements can be extrapolated, we compared our JingNing results with those of other population surveys $[6,10-12,14,16]$. The key finding of our research was that whereas ambulatory blood pressure means by and large were of the same order of magnitude across populations, one should not take the generalizability of epidemiological observations on ambulatory blood pressure monitoring for granted. Indeed, the application of fixed clock-time intervals to determine the daytime and night-time ambulatory blood pressures must account for the lifestyle of the population under study. Moreover, in our JingNing individuals, diastolic blood pressure during the whole day and at night was from 1 to $4 \mathrm{mmHg}$ and from 3 to $7 \mathrm{mmHg}$ higher than in all other population studies $[6,10-12,16]$ with the exception of one survey in Taiwan [14].

The awake or out-of-bed and asleep or in-bed blood pressures are usually considered to be the best standard to analyze ambulatory blood pressure recordings in terms of human diurnal activity [34]. However, they add to the complexity of the analysis and errors may occur in the notation of the exact times of individuals going to bed and getting up. Daytime and night-time ambulatory blood pressure means computed from fixed clock-time intervals can reasonably approach the awake and asleep blood pressures. However, wide fixed 
Table 3 Systolic/diastolic pressures $(\mathrm{mmHg})$ in 239 normotensive individuals

\begin{tabular}{|c|c|c|c|c|c|c|c|c|c|}
\hline & \multicolumn{4}{|c|}{ Men } & \multicolumn{4}{|c|}{ Women } & \multirow[t]{2}{*}{ Both sexes } \\
\hline & $\leq 39$ years & $40-59$ years & $\geq 60$ years & All men & $\leq 39$ years & $40-59$ years & $\geq 60$ years & All women & \\
\hline $\begin{array}{l}\text { Number } \\
\text { Conventional }\end{array}$ & 63 & 31 & 19 & 113 & 76 & 39 & 11 & 126 & 239 \\
\hline Mean & $116 / 75$ & $120 / 79$ & $122 / 74$ & $118 / 76$ & $110 / 73$ & $120 / 75$ & $121 / 73$ & $114 / 73$ & $116 / 74$ \\
\hline SD & $11 / 8$ & $10 / 8$ & $9 / 5$ & $11 / 8$ & $11 / 9$ & $12 / 9$ & $13 / 9$ & $12 / 9$ & $12 / 8$ \\
\hline$P_{5}$ & $98 / 60$ & $105 / 63$ & $105 / 64$ & $101 / 62$ & $91 / 58$ & $100 / 56$ & $96 / 61$ & $94 / 59$ & $96 / 59$ \\
\hline$P_{50}$ & $115 / 75$ & $120 / 80$ & $123 / 76$ & $118 / 76$ & $110 / 74$ & $120 / 75$ & $126 / 73$ & $114 / 74$ & $116 / 75$ \\
\hline$P_{90}$ & $130 / 86$ & $134 / 88$ & $134 / 80$ & $132 / 86$ & $124 / 84$ & $136 / 87$ & $134 / 85$ & $131 / 86$ & $132 / 86$ \\
\hline $\begin{array}{c}\mathrm{P}_{95} \\
\text { Daytime }\end{array}$ & $137 / 88$ & $135 / 89$ & $138 / 81$ & $137 / 88$ & $130 / 88$ & $138 / 89$ & $134 / 89$ & $135 / 88$ & $136 / 88$ \\
\hline Mean & $120 / 77$ & $124 / 83$ & $123 / 78$ & $122 / 79$ & $114 / 75$ & $119 / 79$ & $116 / 76$ & $116 / 76$ & $119 / 78$ \\
\hline SD & $9 / 7$ & $9 / 7$ & $10 / 8$ & $9 / 8$ & $8 / 6$ & $9 / 8$ & $13 / 8$ & $9 / 7$ & $9 / 7$ \\
\hline$P_{5}$ & $106 / 65$ & $108 / 72$ & $111 / 68$ & $107 / 68$ & $99 / 66$ & $105 / 66$ & $98 / 60$ & $100 / 66$ & $104 / 67$ \\
\hline$P_{50}$ & $119 / 77$ & $125 / 82$ & $122 / 77$ & $122 / 78$ & $113 / 74$ & $120 / 81$ & $118 / 75$ & $116 / 76$ & $119 / 77$ \\
\hline$P_{90}$ & $131 / 88$ & $134 / 92$ & $141 / 91$ & $134 / 89$ & $123 / 83$ & $130 / 91$ & $134 / 86$ & $127 / 85$ & $131 / 88$ \\
\hline $\begin{array}{c}\mathrm{P}_{95} \\
\text { Night-time }\end{array}$ & $136 / 89$ & $138 / 93$ & $143 / 97$ & $138 / 92$ & $127 / 85$ & $136 / 93$ & $139 / 90$ & $130 / 89$ & $136 / 91$ \\
\hline Mean & $105 / 64$ & $108 / 71$ & $116 / 70$ & $108 / 67$ & $99 / 62$ & $106 / 69$ & $112 / 68$ & $102 / 64$ & $105 / 66$ \\
\hline SD & $8 / 8$ & $9 / 7$ & $14 / 9$ & $11 / 9$ & $8 / 6$ & $11 / 9$ & $14 / 7$ & $10 / 8$ & $11 / 8$ \\
\hline$P_{5}$ & $88 / 50$ & $94 / 61$ & $93 / 59$ & $92 / 54$ & $86 / 52$ & $92 / 55$ & $86 / 55$ & $87 / 54$ & $88 / 53$ \\
\hline$P_{50}$ & $105 / 63$ & $108 / 72$ & $112 / 69$ & $107 / 65$ & $97 / 61$ & $103 / 67$ & $109 / 69$ & $101 / 63$ & $103 / 64$ \\
\hline$P_{90}$ & $114 / 76$ & $121 / 79$ & $141 / 83$ & $121 / 78$ & $109 / 70$ & $121 / 85$ & $130 / 76$ & $119 / 75$ & $119 / 77$ \\
\hline $\begin{array}{l}\mathrm{P}_{95} \\
\text { Whole day }\end{array}$ & $117 / 78$ & $126 / 82$ & $150 / 89$ & $126 / 81$ & $113 / 75$ & $125 / 86$ & $131 / 79$ & $122 / 79$ & $125 / 81$ \\
\hline Mean & $115 / 72$ & $119 / 79$ & $120 / 74$ & $117 / 74$ & $108 / 70$ & $115 / 75$ & $115 / 72$ & $111 / 72$ & $114 / 73$ \\
\hline SD & $8 / 7$ & $8 / 6$ & $10 / 7$ & $8 / 7$ & $7 / 5$ & $9 / 7$ & $11 / 7$ & $9 / 7$ & $9 / 7$ \\
\hline$P_{5}$ & $102 / 63$ & $103 / 68$ & $105 / 63$ & $103 / 64$ & $96 / 62$ & $102 / 64$ & $101 / 62$ & $99 / 63$ & $100 / 63$ \\
\hline$P_{50}$ & $114 / 71$ & $120 / 79$ & $115 / 73$ & $116 / 73$ & $108 / 70$ & $114 / 76$ & $112 / 72$ & $110 / 71$ & $113 / 72$ \\
\hline$P_{90}$ & $124 / 82$ & $129 / 88$ & $135 / 85$ & $128 / 84$ & $117 / 77$ & $129 / 86$ & $129 / 81$ & $123 / 80$ & $126 / 82$ \\
\hline$P_{95}$ & $128 / 84$ & $130 / 90$ & $137 / 91$ & $130 / 88$ & $120 / 79$ & $129 / 91$ & $137 / 85$ & $127 / 84$ & $129 / 86$ \\
\hline
\end{tabular}

Normotension was defined as a systolic pressure $<140 \mathrm{mmHg}$ and a diastolic pressure $<90 \mathrm{mmHg}$ on conventional blood pressure measurement at home (average of five readings in the sitting position). Daytime ranged from 0800 to $1800 \mathrm{~h}$ and night-time from 2200 to $0400 \mathrm{~h}$.

Table 4 Differences between the conventional and daytime blood pressures according to hypertension and treatment status

\begin{tabular}{lccc}
\hline & $n$ & Difference in systolic blood pressure $^{\mathrm{a}}$ & Difference in diastolic blood pressure $^{\mathrm{a}}$ \\
\hline Normotensive subjects & 239 & $-2.7(-4.0$ to -1.4$)$ & $-3.1(-4.1$ to -2.2$)$ \\
Hypertensive patients & 117 & $14.9(11.5-18.3)^{\mathrm{b}}$ & $1.3(-0.4 \text { to } 3.0)^{\mathrm{b}}$ \\
Untreated & 67 & $15.9(12.2-19.6)^{\mathrm{b}}$ & $1.7(-0.2 \text { to } 3.5)^{\mathrm{b}}$ \\
Treated & 50 & $13.6(7.2-20.0)^{\mathrm{b}}$ & $0.8(-2.3 \text { to } 4.0)^{\mathrm{b}}$ \\
\hline
\end{tabular}

${ }^{a}$ Values are mean differences (conventional minus daytime blood pressure) with $95 \%$ confidence interval.

${ }^{\mathrm{b}} P<0.01$, compared to normotensive individuals.

clock-time methods, which embrace the whole day $(24 \mathrm{~h})$ always include variable portions of the actual awake and asleep periods and therefore introduce inaccuracy in the analysis. In contrast, narrow fixed clock-time intervals substantially reduce this error and yield daytime and night-time blood pressures means, which approximate to the average awake and asleep values $[35,36]$. In the present study, we confirmed this concept. Indeed, irrespective of hypertension status, the means computed from short fixed clock-time intervals were within $0.5 \mathrm{mmHg}$ of those determined by the diary method. Although small, some of these differences attained statistical significance, because of the relatively large number of individuals enrolled in our study. In our previous publications [12,32,33], daytime and night-time were defined as the intervals ranging from 1000 to $2000 \mathrm{~h}$ and from midnight to $0600 \mathrm{~h}$, respectively. However, this definition clearly deviated from the diurnal activity pattern of our JingNing population. Had we not accounted for the difference in lifestyle, by applying the previously published intervals [12,32,33], we would have inflated the differences between the blood pressure means determined by the diary method as compared with those computed from short fixed clock-time intervals. We therefore re-defined daytime and night-time as intervals ranging from 0800 to $1800 \mathrm{~h}$ and from 2200 to $0400 \mathrm{~h}$, respectively.

In our study, compared with the daytime means, the conventional blood pressure measured at home by physicians was $2.7 / 3.1 \mathrm{mmHg}$ lower in 239 normotensive individuals, but $14.9 / 1.3 \mathrm{mmHg}$ higher in 117 hypertensive patients. Thus, in line with previous publications [12,21,32], including the International Database on Ambulatory Blood Pressure Monitoring [37], our study confirmed that normotensive individuals usually have a 
Table 5 The conventional (CBP) and ambulatory blood pressures (ABP) in normotensive participants enrolled in seven population studies

\begin{tabular}{|c|c|c|c|c|c|c|c|}
\hline Study & BPS & $\mathrm{EPOGH}^{\mathrm{a}}$ & AlB & PAMELA & OHASAMA & Taiwan & JingNing \\
\hline Setting & rural & rural/urban & urban & urban & rural & rural/urban & rural \\
\hline Normotensive subjects & 729 & 931 & 777 & 1225 & 335 & 720 & 231 \\
\hline $\begin{array}{l}\text { Mean age (range, } \\
\text { years) }\end{array}$ & $50(20-87)$ & $35(20-74)$ & $45(25-51)$ & $46(25-64)$ & $54(\geq 20)$ & $51(\geq 30)$ & $42(20-81)$ \\
\hline Women (\%) & $53 \%$ & $58 \%$ & $52 \%$ & $51 \%$ & $68 \%$ & $49 \%$ & $53 \%$ \\
\hline \multicolumn{8}{|l|}{ CBP } \\
\hline Mean & $118 / 74$ & $118 / 75$ & $115^{\mathrm{BE}} / 73^{\mathrm{E}}$ & $115^{\mathrm{BE}} / 72^{\mathrm{BE}}$ & $121^{\mathrm{BEAP}} / 70^{\mathrm{BEAP}}$ & $119^{\mathrm{EAP}} / 74^{\mathrm{PO}}$ & $116^{\mathrm{OT}} / 75^{\mathrm{PO}}$ \\
\hline SD & $10 / 8$ & $11 / 8$ & $11 / 8$ & $13 / 9$ & $12 / 10$ & $11 / 8$ & $12 / 8$ \\
\hline $\begin{array}{l}\mathrm{P}_{95} \\
24-\mathrm{h} \text { ABP }\end{array}$ & $136 / 86$ & $135 / 87$ & $132 / 85$ & $138 / 87$ & - & - & $136 / 88$ \\
\hline Mean & $115 / 70$ & $116 / 70$ & $116 / 71^{\mathrm{BE}}$ & $115 / 72^{\text {BEA }}$ & $116 / 69^{\mathrm{AP}}$ & $116 / 73^{\text {BEAPO }}$ & $114^{\mathrm{EA}} / 73^{\mathrm{BEAO}}$ \\
\hline SD & $8 / 6$ & $9 / 6$ & $9 / 6$ & $8 / 6$ & $10 / 7$ & $10 / 7$ & $9 / 7$ \\
\hline$P_{95}$ & $129 / 80$ & $131 / 81$ & $130 / 82$ & $128 / 82$ & $139 / 81$ & - & $129 / 86$ \\
\hline \multicolumn{8}{|l|}{ Daytime } \\
\hline SD & $9 / 7$ & $10 / 7$ & $10 / 7$ & $9 / 7$ & $11 / 7$ & $10 / 7$ & $10 / 7$ \\
\hline$P_{95}$ & $137 / 88$ & $139 / 87$ & $137 / 88$ & $134 / 88$ & - & - & $136 / 91$ \\
\hline \multicolumn{8}{|l|}{ Night-time } \\
\hline Mean & $104 / 60$ & $105 / 61^{\mathrm{B}}$ & $104 / 59^{\mathrm{E}}$ & $105^{\mathrm{BA}} / 63^{\mathrm{BEA}}$ & $106^{\mathrm{BA}} / 61^{\mathrm{AP}}$ & $114^{\mathrm{BEAPO}} / 71^{\mathrm{BEAPO}}$ & $105^{\top} / 66^{\text {BEAPOT }}$ \\
\hline SD & $9 / 7$ & $10 / 7$ & $9 / 7$ & $9 / 7$ & $11 / 7$ & $11 / 7$ & $11 / 8$ \\
\hline$P_{95}$ & $121 / 72$ & $122 / 74$ & $120 / 71$ & $121 / 74$ & - & - & $125 / 81$ \\
\hline
\end{tabular}

Acronyms and references: BPS, Belgian population study [12]; EPOGH, European Project on Genes of Hypertension [16]; AIB, Allied Irish Bank Study [6]; PAMELA, Pressioni Arteriose Monitorate E Loro Associazioni, Monza, Italy [11]; OHASAMA, survey conducted in Ohasama, Iwate Prefecture, 100 km north of Sendai, Japan [10]; Taiwan, study conducted on the Taiwan and Kinmen (Quemoy) islands [14].

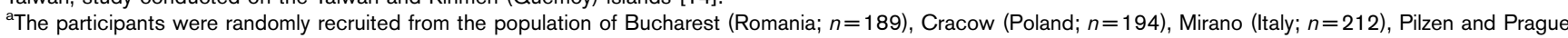
(Czech Republic; $n=223$ ), and Novosibirsk (Russia; $n=212$ ). $P$-values for the between-population differences were adjusted for multiple comparisons by Bonferroni's method. B, $P \leq 0.05$ vs BPS; E, $P \leq 0.05$ versus EPOGH; A, $P \leq 0.05$ versus AIB $; \mathrm{P}, P \leq 0.05$ versus PAMELA; $\mathrm{O}, P \leq 0.05$ versus $\mathrm{OHASAMA}$; and $\mathrm{T}, P \leq 0.05$ versus Taiwan.

higher daytime ambulatory than conventional blood pressure, whereas hypertensive patients, confronted with a doctor, often experience a white-coat effect and therefore have the higher levels on conventional measurement [38]. In keeping with other population studies $[12,32]$, we also confirmed that in Chinese age is a much stronger determinant of the conventional than the ambulatory systolic pressure.

Why the 24-h and night-time diastolic blood pressures were higher in Chinese individuals recruited in JingNing and Taiwan [14] compared with Caucasians [6,11,12,16] and Japanese [10] remains to be elucidated. We do not believe that these findings just arose from random variability, because they were consistent across two independent studies in Chinese. Our study does not allow us to clarify to what extent genetic determinants, lifestyle, environmental factors, or a combination thereof underlie the higher diastolic blood pressure in Chinese. However, according to current hemodynamic concepts, diastolic and mean blood pressure reflect peripheral arterial resistance, whereas systolic blood pressure behaves as a dynamic index of the coupling between left ventricular ejection and the distensibility of the large arteries [39]. Several lines of evidence suggest that Asians compared with Caucasians have lower renin activity and are more susceptible to a volume-dependent type of hypertension [40]. If these assumptions apply, sodium homeostasis in Chinese might be more dependent on pressure natriuresis, which in turn might explain the higher night-time diastolic blood pressure. Interestingly, several investigators noticed that Blacks, an ethnic group also characterized by low renin activity, also have higher night-time blood pressure than White individuals $[41,42]$. Whatever the underlying mechanism, the present findings raise the issue of the generalizability of the distributional characteristics of the ambulatory blood pressure across population.

The present study has to be interpreted within the context of its limitations. It is an ongoing project. According to epidemiological standards, our present report is based on a relatively small sample size. Our findings might not be applicable to the majority of Chinese who belong to the Han ethnicity. On the other hand, we applied a validated protocol of phenotyping and we maintained a strict quality control program [16]. For blood pressure measurement, we strictly adhered to the recommendations of European Society of Hypertension [3]. For ambulatory monitoring, we used validated and calibrated SpaceLabs recorders [43].

In conclusion, we demonstrated significant differences in the characteristics of the ambulatory blood pressure across Asian and Caucasian populations. However, to what extent different activity patterns and genetic and environmental factors explain this context-dependency remains to be clarified. If confirmed, our observations suggest that statistical parameters of ambulatory blood pressure measurements should be internally validated 
within ethnicities and populations. Moreover, working definitions of normality derived from the distribution of the ambulatory blood pressure in normotensive individuals always need further validation in terms of cardiovascular complications.

\section{Contributors}

P.G. and J.A.S, raised funding. D.Z. organized and supervised the study in China. J.-G.W. and Y.L. coordinated the acquisition of the data, and together with J.A.S. constructed the database, performed the statistical analysis and wrote the first draft of the manuscript. All named authors critically revised the manuscript for important intellectual content, took part in the interpretation of the results and prepared the final version of the manuscript.

\section{Acknowledgements}

The JingNing Study would not have been possible without the voluntary collaboration of the participants. The authors gratefully acknowledge the support provided by Shengping Qiu, Peiling Xia (Health Bureau, JingNing County, Zhejiang Province, China) and Changsheng $\mathrm{Hu}$ (People's Hospital, JingNing County, Zhejiang Province, China). The authors are also grateful for the expert assistance of Lihua Li, Xuemei Luo, Shouyu Mao, Weizhong Zhang, and Huaifa Zhou (Shanghai Institute of Hypertension, Shanghai, China), Jingfeng Hua, Yixin Lan, Baolin Ye, and Xiaomei Ye (primary care physicians of JingNing County, Zhejiang Province, China), and Sandra Covens, Lieve Gijsbers, Sylvia Van Hulle, and Renilde Wolfs (Study Coordinating Centre, Leuven, Belgium).

\section{References}

1 Staessen JA, Wang J, Bianchi G, Birkenhäger WH. Essential hypertension. Lancet 2003; 361:1629-1641.

2 O'Brien E. Ambulatory blood pressure monitoring in the management of hypertension. Heart 2003; 89:571-576.

3 O'Brien E, Asmar R, Beilin L, Imai Y, Mallion JM, Mancia G, et al. European Society of Hypertension recommendations for conventional, ambulatory and home blood pressure measurement. J Hypertens 2003; 21:821-848.

4 Chobanian AV, Bakris GL, Black HR, Cushman WC, Green LA, Izzo JL, Jr., et al. The Seventh Report of the Joint National Committee on Prevention, Detection, Evaluation, and Treatment of High Blood Pressure: the JNC 7 report. JAMA 2003; 289:2560-2572.

5 James GD, Moucha OP, Pickering TG. The normal hourly variation of blood pressure in women : average patterns and the effect of work stress. $J$ Hum Hypertens $1991 ;$ 5:505-509.

6 O'Brien E, Murphy J, Tyndall A, Atkins N, Mee F, McCarthy G, et al. Twentyfour-hour ambulatory blood pressure in men and women aged 17 to 80 years: the Allied Irish Bank Study. J Hypertens 1991; 9:355-360.

7 Staessen J, Guo C, De Cort P, Fagard R, Lijnen P, Thijs L, et al. Mean and range of the ambulatory pressure in normotensive subjects. Chin Med $\mathrm{J}$ 1992; 105:328-333.

8 Thijs L, Amery A, Clement D, Cox J, De Cort P, Fagard R, et al. Ambulatory blood pressure monitoring in elderly patients with isolated systolic hypertension. J Hypertens 1992; 10:693-699.

9 Mancia G, Omboni S, Ravogli A, Parati G, Zanchetti A. Ambulatory blood pressure monitoring in the evaluation of antihypertensive treatment: additional information from a large data base. Blood Press 1995; 4: $148-159$
10 Imai $Y$, Nagai K, Sakuma M, Sakuma H, Nakatsuka $H$, Satoh $H$, et al. Ambulatory blood pressure of adults in Ohasama, Japan. Hypertension 1993; 22:900-912.

11 Sega R, Bravi C, Cesana G, Valagussa F, Mancia G, Zanchetti A. Ambulatory and home blood pressure normality: The Pamela Study. J Cardiovasc Pharmacol 1994; 23(suppl 5):S12-S15.

12 Staessen JA, Bieniaszewski L, O'Brien ET, Imai Y, Fagard R. An epidemiological approach to ambulatory blood pressure monitoring: the Belgian population study. Blood Press Monit 1996; 1:13-26.

13 Wiinberg N, Hoegholm A, Christensen HR, Bang LE, Mikkelsen KL, Ebbe Nielsen $\mathrm{P}$, et al. 24-h ambulatory blood pressure in 352 normal Danish subjects, related to age and gender. Am J Hypertens 1995; 8: 978-986.

14 Chen CH, Ting CT, Lin SJ, Hsu TL, Chou P, Kuo HS, et al. Relation between diurnal variation of blood pressure and left ventricular mass in a Chinese population. Am J Cardiol 1995; 75:1239-1243.

15 Manning G, Rushton L, Millar-Craig MW. Twenty-four hour ambulatory blood pressure: a sample from a normal British population. J Hum Hypertens 1998; 12:123-127.

16 Kuznetsova T, Staessen JA, Kawecka-Jaszcz K, Babeanu S, Casiglia E, Filipovsky J, et al. Quality control of the blood pressure phenotype in the European Project on Genes in Hypertension. Blood Press Monit 2002; 7:215-224.

17 Rasmussen SL, Torp-Pedersen C, Borch-Johnsen K, Ibsen H. Normal values for ambulatory blood pressure and differences between casual blood pressure and ambulatory blood pressure: results from a Danish population survey. J Hypertens 1998; 16:1415-1424.

18 Perloff $\mathrm{D}$, Sokolow M, Cowan R. The prognostic value of ambulatory blood pressures. JAMA 1983; 249:2792-2798.

19 Redón J, Campos C, Narciso ML, Rodicio JL, Pascual JM, Ruilope LM. Prognostic value of ambulatory blood pressure monitoring in refractory hypertension. A prospective study. Hypertension 1998; 31:712-718.

20 Khattar RS, Senior R, Lahiri A. Cardiovascular outcome in white-coat versus sustained mild hypertension. A 10-year follow-up study. Circulation 1998; 98:1892-1897.

21 Staessen JA, Thijs L, Fagard R, O'Brien ET, Clement D, de Leeuw PW, et al. Predicting cardiovascular risk using conventional vs ambulatory blood pressure in older patients with systolic hypertension. JAMA 1999; 282:539-546.

22 Khattar RS, Swales JD, Banfield A, Dore C, Senior R, Lahiri A. Prediction of coronary and cerebrovascular morbidity and mortality by direct continuous ambulatory blood pressure monitoring. Circulation 1999; 100: 1071-1076.

23 Staessen JA, Thijs L, O'Brien ET, Bulpitt CJ, de Leeuw PW, Fagard RH, et al. Ambulatory pulse pressure as predictor of outcome in older patients with systolic hypertension. Am J Hypertens 2002; 15(part 1):835-843.

24 Clement DL, De Buyzere ML, De Bacquer DA, de Leeuw PW, Duprez DA Fagard $\mathrm{RH}$, et al. Prognostic value of ambulatory blood-pressure recordings in patients with treated hypertension. N Engl J Med 2003; 348: 2407-2415.

25 Ohkubo T, Hozawa A, Nagai K, Kikuya M, Tsuji I, Ito S, et al. Prediction of stroke by ambulatory blood pressure monitoring versus screening blood pressure measurements in a general population: the Ohasama study. J Hypertens 2000; 18:847-854.

26 Petrie JC, O'Brien ET, Littler WA, de Swiet M. Recommendations on blood pressure measurement by a working party of the British Hypertension Society. BMJ 1989; 293:611-615.

27 Thijs L, Staessen J, Fagard R. Analysis of the diurnal blood pressure curve. High Blood Press Cardiovasc Prev 1992; 1:17-28.

28 Shapiro SS, Wilk MB. An analysis of variance test for normality (complete samples). Biometrika 1965; 52:591-611.

29 Snedecor GW, Cochran WG. Statistical methods, 7th edn. Ames, lowa, USA: The lowa State University Press; 1980.

30 The SAS Institute Inc.: The REG procedure. In: SAS/STAT user's guide, version 6, volume 2, GLM-VARCOMP. 4 edn. Cary, North Carolina, USA: The SAS Institute Inc; 1995, pp. 1350-1456.

31 Kleinbaum DG, Kupper LL, Muller KE. Applied regression analysis and other multivariate methods, 2nd edn. Boston, Massachusetts, USA: PWS-Kent Publishing Company; 1988.

32 Kuznetsova T, Malyutina S, Pello E, Thijs L, Nikitin Y, Staessen JA. Ambulatory blood pressure of adults in Novosibirsk, Russia : interim report on a population study. Blood Press Monit 2000; 5:291-296.

33 Fagard RH, Staessen JA, Thijs L, Bulpitt CJ, Clement D, de Leeuw PW, et al. Relationship between ambulatory blood pressure and follow-up clinic blood pressure in elderly patients with systolic hypertension. J Hypertens 2004; 22:81-87. 
34 Pickering TG. How should the diurnal changes of blood pressure be expressed? Am J Hypertens 1995; 8:681-682.

35 Fagard R, Brguljan J, Thijs L, Staessen J. Prediction of the actual awake and asleep blood pressures by various methods of $24 \mathrm{~h}$ pressure analysis. J Hypertens 1996; 14:557-563.

36 Fagard $\mathrm{RH}$, Staessen JA, Thijs L. Optimal definition of daytime and nighttime blood pressure. Blood Press Monit 1997; 2:315-321.

37 Staessen JA, O'Brien ET, Amery AK, Atkins N, Baumgart P, De Cort P, et al. Ambulatory blood pressure in normotensive and hypertensive subjects: results from an international database. J Hypertens 1994; 12(suppl 7): S1-S12.

38 Staessen JA, Den Hond E, Celis H, Fagard R, Keary L, Vandenhoven G, et al. Antihypertensive treatment based on blood pressure measurement at home or in the physician's office. A randomized controlled trial. JAMA 2004; 291:955-964.
39 Mayet J, Hughes A. Cardiac and vascular pathophysiology in hypertension. Heart 2003; 89:1104-1109.

40 Katsuya T, Ishikawa K, Sugimoto K, Rakugi H, Ogihara T. Salt sensitivity of Japanese from the viewpoint of gene polymorphism. Hypertens Res 2003; 26:521-525.

41 Gretler DD, Fumo MT, Nelson KS, Murphy MB. Ethnic differences in circadian hemodynamic profile. Am J Hypertens 1994; 7:7-14.

42 Harshfield GA, Treiber FA, Wilson ME, Kapuku GK, Davis HC. A longitudinal study of ethnic differences in ambulatory blood pressure patterns in youth. Am J Hypertens 2002; 15:525-530.

43 O'Brien E, Waeber B, Parati G, Staessen J, Myers MG, on behalf of the European Society of Hypertension Working Group on Ambulatory Blood Pressure Monitoring. Blood pressure measuring devices: recommendations of the European Society of Hypertension. BMJ 2001; 322:531-536. 